\title{
Enhancing Active Learning Methods in Department of Physics Students in Wolaita Sodo University
}

\author{
Takele Teshome Somano, Yeshanew Fikre Ololo
}

Department of Physics, Wolaita Sodo University, Sodo, Ethiopia

\section{Email address:}

takeleteshome36@gmail.com (T. T. Somano)

\section{To cite this article:}

Takele Teshome Somano, Yeshanew Fikre Ololo. Enhancing Active Learning Methods in Department of Physics Students in Wolaita Sodo University. Higher Education Research. Vol. 6, No. 4, 2021, pp. 86-92. doi: 10.11648/j.her.20210604.12

Received: July 30, 2021; Accepted: August 12, 2021; Published: August 23, 2021

\begin{abstract}
It is well known that our country's education is entangled with complex problems of relevance, quality, accessibility and equity. This traditional pedagogy has been identified as one of the major reasons adversely impacting student engagement and motivation in different fields. The main aim of the current study was to promote active learning methods in the Department of physics students of Wolaita Sodo University. A descriptive survey research design was employed. Data were collected from primary sources through the questionnaire and observation. Among the department of physics students, 10 instructors and 36 students were selected using Yamane's formula. Self-administered questionnaire was used to assess teachers' practice of active learning methods and classroom observation. There was deviation (Std. Dev.=2.295) between the practice of ALMs and the response and the $p$-value $(p=0.001)$ indicated the presence of significant association between the ALMs and the responses of students and also the observation but there was insignificant association in the response of teachers and ALMs. The major challenges of implementing ALMs are inability of students, students' negative attitude, students' poor attention, and language barriers. Therefore, training should be prepared for instructors to enhance ALMs that are least practiced by the instructors as well as to create awareness.
\end{abstract}

Keywords: Active Learning Methods, Promoting, Wolaita Sodo University

\section{Introduction}

\subsection{Background of the Study}

It is known that our country's education is entangled with complex problems of relevance, quality, accessibility and equity. The objectives of education do not take cognizance of the society's needs and do not adequately indicate future direction. The absence of interrelated contents and mode of presentation that can develop students' knowledge, cognitive abilities and behavioral change by level, to adequately enrich problem-solving ability and attitude, are some of the major problems of our education system [8].

An extensive study conducted by the Ministry of Education [10] revealed that Ethiopian teacher educators failed to form a spearhead in educational development endeavors. According to the study, classes were dominated by traditional teaching methods, i.e. they were not studentcentered and not truly engaging. The study revealed that teacher educators have received very little or no opportunity of training by which they build their professional qualities so that they can address the needs of their students and of society. As a result, the Higher Diploma Program has been introduced by the Ministry of Education (MoE) to higher education institutions to maintain the quality of education.

The Higher Diploma Program (HDP) is a professional development course designed twelve years ago with the demand of the Ethiopian MoE, by Voluntary Services Overseas (VSO) volunteers, working in cooperation with Ethiopian educators $[8,17]$. The aim of the Higher Diploma Program is to improve the quality of education in Ethiopia through a licensing Programme that will develop the skills and professionalism of teacher educators.

\subsection{Statement of the Problem}

Active Learning is a process wherein students are actively engaged in building understanding of facts, ideas, and skills through the completion of instructor directed tasks and activities. It is any type of activity that gets students involved in the 
learning process. The traditional pedagogy has been identified as one of the major reasons adversely impacting student engagement and motivation in different fields. Research on learning provides strong evidence that active learning can have a positive impact on student learning outcomes. The biggest challenge with incorporating active-learning strategies in the classroom is the time constraint of the traditional class period. This paper shares ideas of promoting active learning methods (ALMs) on academic achievement of students.

\subsection{Objectives}

\subsubsection{General Objective}

The general objective of this study was to enhance active learning methods in the Department of physics students of Wolaita Sodo University.

\subsubsection{Specific Objectives}

The specific objectives of the study were to:

Assess active learning methods implemented in the classroom.

Identify the major challenges that hinder the implementation of active learning methods.

\subsection{Research Questions}

What are the types of active learning methods implemented in the Department of Physics class rooms?

What are the major challenges faced to implement active learning methods?

\subsection{Significance of the Study}

The study is used as a: Baseline to enhance implementation of active learning methods in the classroom.

The study is used as a means to confirm the efforts being made by teachers to ensure quality of education.

The study indicates the challenges that hinder active learning methods to improve the problems.

\subsection{Scope of the Study}

This study was conducted in the Wolaita Sodo University, the Department of Physics students.

\section{Review of Related Literature}

\subsection{Conceptualizing Active Learning Methods}

The scholars described active learning strategies as those that involve "students in doing things and (have the students) think about the things they are doing" In an effective learning environment [1, 4, 12]. Investigators suggested that active participation strengthens learning regardless of environment [7]; active learning requires "intellectual effort, encouraging higher-order thinking (analysis, synthesis, evaluation)" and provides a means for the learner to assimilate, apply, and retain learning [4].

Active learning includes all the components of the instructional process where students do something to realize the goals of learning. When students learn with the help of active learning strategies, they are not simply learning subject matters but they apply concepts and explore relationships between concepts, facts and contrasting points of views coming from different socio-cultural settings [5]. This interaction in the views of Barrette [3] is instrumental to construct knowledge for them rather than simply receive knowledge from the instructor. With the help of active learning strategies, the teacher does have the opportunity of tangible information about the contribution of learners in the teaching learning process and this helps him to gear the process towards meeting the needs of each student by making use of the feedback generated from evaluating the teaching learning context. This is because the applications of such teaching strategies yield live evidence about the process of learning and the potential each student has to learn the subject under consideration [2].

\subsection{Benefits of Active Learning Methods}

According to [1], active learning draws upon the concept of experiential learning where knowledge is constructed through the transformation of experience. One scholar stated that active learning techniques take advantage of what is termed as the "generation effect" in learning and human memory [8, 6, 11, 14, 15].

American Psychological Association, [12] stated that the learning of complex subject matters is most effective when learning is an internal process of constructing meaning from information and experience. As compared to the traditional lecture-based approach in which students are passive recipients of information, active learning strategies emphasize constructivist qualities such as independent inquiry and the structuring and restructuring of knowledge [7]. Attard et al. [9] suggest that students retain information better and develop better high-level thinking skills when active learning methods are used.

Weimer noted that identifying the learning styles of students and getting knowledge is a key to effective education [10]. He also concludes that "those who accept the premise that different students will learn in different ways will find that active learning strategies not only enliven the classroom but significantly improve their students' thinking and learning capabilities by gearing their lessons towards addressing the learning style of their students.

\subsection{Basic Active Learning Techniques}

The most common and basic active learning techniques that are suggested by $\mathrm{MoE}$ [8] are, Visual Aids, Gapped Lectures, Buzz Group, Questions and Answers, Active Listening, Written Material, Research, Demonstrations, Interactive Learning, Independent learning, Pair work, Pyramiding, Group work, Jigsaw groups, Cross over groups, and Cooperative learning.

\subsection{Dilemmas of Using Active Learning Methods}

According to [2] the implementation of active learning 
methods is getting resistance from some of those central stakeholders of educational systems that dictate its outcomes i.e., teachers, students and educators. The causes of resistance include:

You can't cover as much course content in classes with the time available.

Devising active learning strategies takes too much preclass preparation.

Large class size prevents implementation of active learning methods.

Most instructors think of themselves as good lecturers

Lack of materials or equipment need to support an active learning approach.

Students resist the employment of active learning methods.

\section{Research Methods}

\subsection{Study Area Description}

Wolaita Sodo University is a public university in Wolaita Sodo, Ethiopia. It is approximately 339 Kilometers far from Addis Ababa, Ethiopia in southwest direction and located at $6^{\circ} 49^{\prime} 44.6^{\prime \prime} \mathrm{N} 37^{\circ} 45^{\prime} 03.5^{\prime \prime} \mathrm{E}$. It is one of the Second Generation Universities of Ethiopia. The university has three campuses: Gandaba Campus, Otona Campus and Tercha Campus. The Ministry of Science and Higher Education of Ethiopian categorized the university under applied institutions. Wolaita Sodo University has 58 undergraduate programs, 43 postgraduate programs, 6 Doctor of Philosophy programs, and 4 Medical specialty programs.

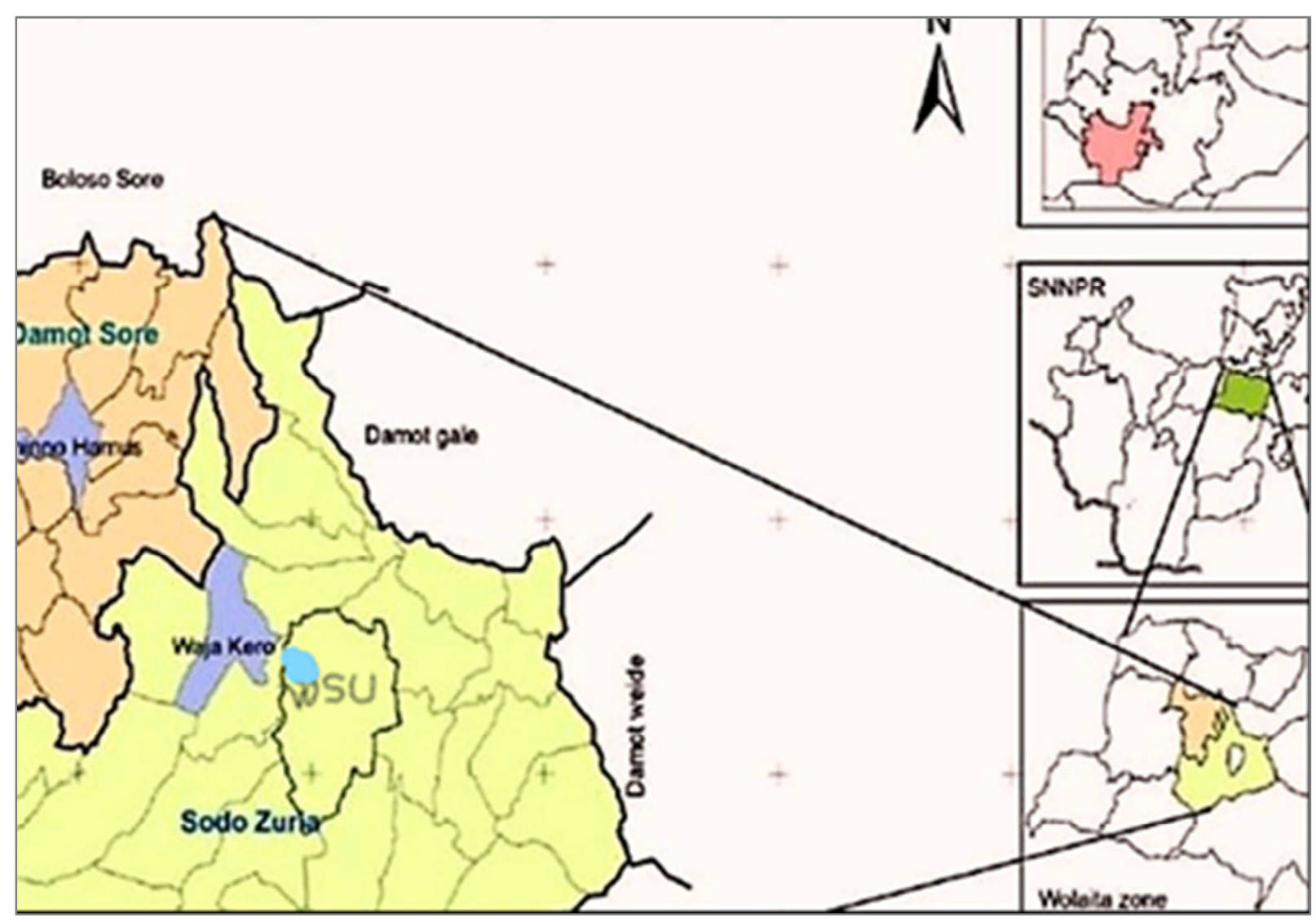

Figure 1. Map of study area.

\subsection{Research Design}

A descriptive survey research design was employed. It was chosen since it is useful to assess whether the instructors implement active learning methods or not. This method was selected because of its usefulness in elucidating the existing situation or phenomenon based on samples that represent a population [5].

\subsection{Population of the Study}

The study was conducted in Wolaita Sodo University in the Department of physics students as a population. In addition to students, teachers who taught in the aforementioned departments were included for the study.

\subsection{Sources of Data}

Data was collected from primary sources through the questionnaire and observation.

\subsection{Sample Size and Sampling Technique}

Among the classes in the Department of physics students were selected randomly. From the specified class consisting of 10 instructors and 40 students, 10 instructors and 36 students were selected using Yamane's formula [13]. 10 questionnaires were distributed for the instructors and 14 questionnaires were prepared for students. 


$$
\mathrm{n}=\mathrm{N} / 1+\mathrm{N}(\mathrm{e})^{2}
$$

Where; $\mathrm{n}=$ sample size, $\mathrm{N}=$ total population, $\mathrm{e}=$ Margin of error $(\alpha=0.05)$.

\subsection{Data Collection Instruments}

Self-administered questionnaire was used to assess teachers' practice of active learning methods. Classroom observation was conducted to see how teachers were implementing active learning methods. According to Robson (2002), "Observation can be used as a supportive or supplementary method to collect data that may complement or set in perspective data obtained by other means."
Observation checklist was prepared by researchers with 'Yes' or 'No' alternatives. A total of one classroom observation was conducted.

\subsection{Method of Data Analysis}

Both quantitative and qualitative methods of data analysis were used to analyze the data. In the quantitative analysis, STATA Software was used for percentage, frequency, mean, standard deviation, and chi-square and t-test analysis. The qualitative data was analyzed on a thematic basis considering the research questions. Based on such analysis, the results were summarized and conclusions were made.

\section{Result and Discussion}

\subsection{Practice of Active Learning Methods}

Table 1. Comparison of ALM with responses of students using paired t-test.

\begin{tabular}{|c|c|c|c|c|c|c|c|}
\hline & Student & & & & & & \\
\hline Variable & Always & Percent & Sometimes & Percent & Never & Percent & \\
\hline Questions- answer & 27 & 9.38 & 3 & 1.04 & 6 & 2.08 & \multirow{8}{*}{$\begin{array}{l}\text { Mean }=4.5 \\
\text { Std. err. }=0.135 \\
\text { Std. Dev. }=2.295 \\
t=18.757 \\
X^{2}=53.29 \\
p=0.001\end{array}$} \\
\hline Assignments & 26 & 9.03 & 4 & 1.39 & 6 & 2.08 & \\
\hline Discussion & 20 & 6.94 & 11 & 3.82 & 5 & 1.74 & \\
\hline Presentation & 18 & 6.25 & 12 & 4.17 & 6 & 2.08 & \\
\hline Brainstorming & 14 & 4.86 & 12 & 4.17 & 10 & 3.47 & \\
\hline Demonstration & 14 & 4.86 & 10 & 3.47 & 12 & 4.17 & \\
\hline Microteaching & 10 & 3.47 & 11 & 3.82 & 15 & 5.21 & \\
\hline Cross-over & 5 & 1.74 & 9 & 3.13 & 22 & 7.64 & \\
\hline
\end{tabular}

Among the ALMs, Question-answer (9.38\%) was the most always practiced method followed by assignments $(9.03 \%)$, but crossover $(1.74 \%)$ was the least practiced method followed by microteaching (3.47\%). Even though there were deviations (Std. Dev. $=2.295)$ between the practice of ALMs and the response, the $p$-value $(p=0.001)$ indicated the presence of significant association between the ALMs and the responses of students.

Table 2. Comparison of ALM with responses of instructors using paired t-test.

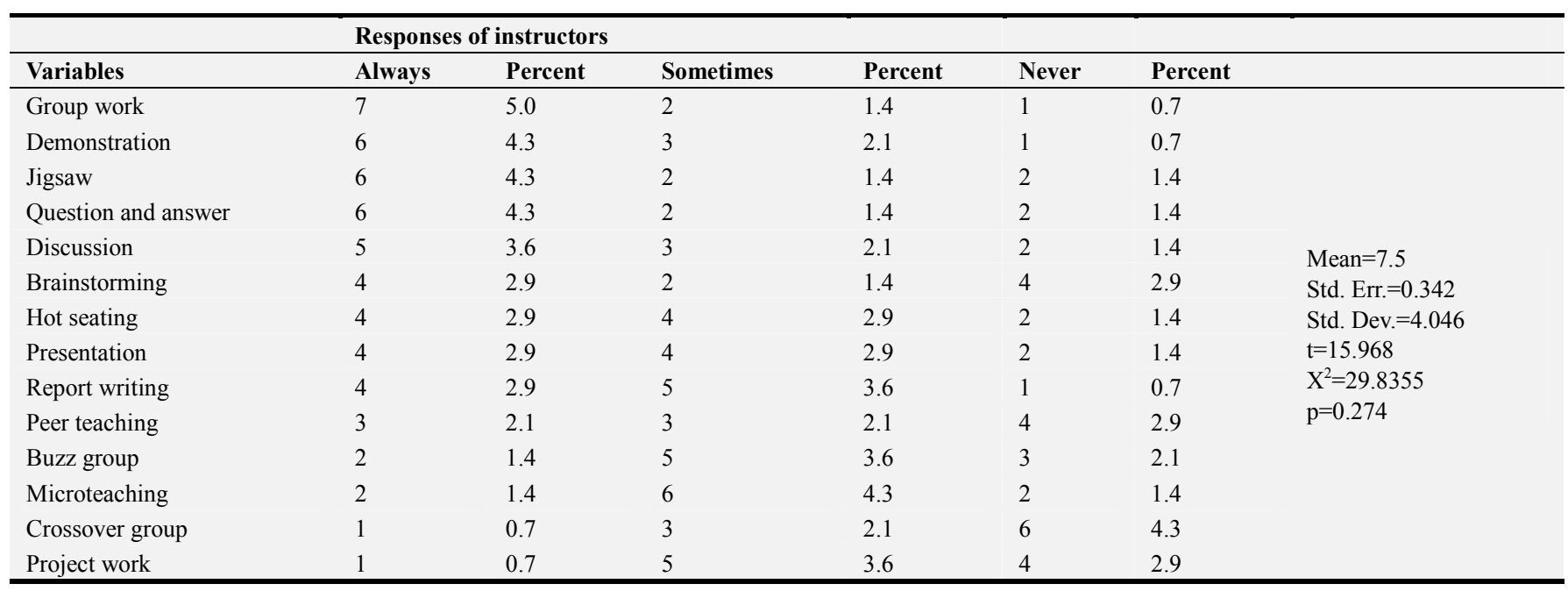

Among the ALMs, group work (5\%) was the most practiced method followed by demonstration (4.3\%), jigsaw (4.3\%), question and answer $(4.3 \%)$; but crossover $(0.7 \%)$ was the least practiced ALM followed by microteaching (1.4\%) and buzz group (1.4\%). The deviation (Std.
Dev. $=4.046$ ) between the ALMs and the response of instructors was greater than that of the finding from students (Std. Dev. $=2.295$ ) but similar with that of the observers (Std. Dev. $=4.046)$. The $p$-value $(p=0.274)$ indicated insignificant association of ALMs and the responses of the instructors. 
Table 3. Comparison of ALM with responses of observers using paired t-test.

\begin{tabular}{llllll}
\hline Responses of classroom observation & & & & & \\
\hline Variables & Yes & Percent & No & Percent & \\
\hline Demonstration & 8 & 5.7 & 2 & 1.4 & \\
Question-answer & 9 & 6.4 & 1 & 0.7 & \\
Group work & 7 & 5.0 & 3 & 2.1 & \\
Buzz group & 3 & 2.1 & 7 & 5.0 & Mean=7.5 \\
Jigsaw & 5 & 3.6 & 5 & 3.6 & Std. Err. $=0.342$ \\
Project work & 8 & 5.7 & 2 & 1.4 & Std. Dev. $=4.046$ \\
Report writing & 8 & 5.7 & 2 & 1.4 & T=17.463 \\
Crossover group & 5 & 3.6 & 5 & 3.6 & X $=37.912$ \\
Discussion & 7 & 5.0 & 3 & 2.1 & P $=0.0001$ \\
Hot seating & 3 & 2.1 & 7 & 5.0 & \\
Presentation & 7 & 5.0 & 3 & 2.1 & \\
Brainstorming & 3 & 2.1 & 7 & 5.0 & \\
Microteaching & 1 & 0.7 & 9 & 6.4 & \\
Peer teaching & 1 & 0.7 & 9 & 6.4 & \\
\hline
\end{tabular}

Among the ALMs, question-answer (6.4\%) was found to be the most practiced method and followed by demonstration (5.7\%), project work (5.7\%), and report writing (5.7\%). But microteaching $(0.7 \%)$ and peer teaching $(0.7 \%)$ methods were found to be the least practiced methods followed by brainstorming $(2.1 \%)$, hot seating $(2.1 \%)$, and buzz group $(2.1 \%)$. Although there was variation in application of ALMs, the $p$-value $(p=0.0001)$ indicated the significant association of ALMs with the observation.

The insignificant association of ALMs and response of instructors at $\alpha=0.05$ has indicated the presence of biasness of response from the instructors. This may be due to unwillingness of instructors to get negative feedback or initiation to get reward hindering their negative sides. Such a kind of action hides evidence about ALMs resulting in a reduction of potential of students to learn the subjects. Similarly, $[13,5,10,16]$ indicated that the applications of ALMs yield live evidence about the process of learning and the potential of each student to learn the subject under consideration.

\subsection{Challenges of Active Learning Methods}

The discussion has been made separately with instructors and students confirmed poor attention of students, negative attitude of students toward group arrangement, fearfulness of students, language inability of students, poor performance of students when compared with the effort of teachers, poor presentation of students, inability of students to communicate with their teachers found to be the main challenges hindering application of ALMs. Most of the challenges to implement ALMs are related to the weakness of students. Similarly, [2, 15] has confirmed the implementation of active learning methods is getting resistance from teachers, students and educators.

\section{Conclusion and Recommendation}

\subsection{Conclusion}

The findings from the above tables indicated that cross- over, microteaching, buzz group, peer teaching, brainstorming, and hot seating identified as the ALMs need great attention because they are reported by the students, the instructors as well as the observers as the least practiced methods. The least application of these methods may be due to lack of training on application of these methods or unwillingness of the instructors. The major challenges of implementing ALMs are inability of students, students' negative attitude, students' poor attention, and language barriers.

\subsection{Implication of This Study}

Application of this action research in this class has brought visible outcomes such as: teachers applied as much as many active learning methods in the classroom, teachers' awareness to act as facilitator in the classroom, student's awareness towards educational outcomes developed, students participate warmly in all works in the class. As we have seen, the discussion we made with teachers and students brought many changes in the teaching learning process of the target classroom. The real witness of what we have seen was the grade change in $45 \%$ of students when we compared with their first semester result.

\subsection{The Next Step of This Study}

Based on the findings of the study, the following next steps of this research were forwarded.

Training should be prepared for instructors to promote ALMs that are practiced by the instructors as well as to create awareness. Most of the challenges to implementing ALMs are related to the skill, attitude, and knowledge of students. Therefore, psychotherapy and speech therapy techniques must be applied to minimize shyness, negative attitude of students, and to improve communication of student.

\subsection{Reflection of the Study}

ALMs are very important methods to promote academic achievement; enhance social interactions among students, 
between students and teachers as well as develop a positive attitude toward the students. Our findings confirmed that some of the ALMs are strongly implemented in the Department of physics students at Wolaita Sodo university and challenges are facing from the part of students. Even though there are so many challenges that are facing in implementing ALMs, trying the best is better rather than completely ignoring it. The future plans and activities of teaching and learning should focus on directly implementing the ALMs because it provides great importance.

\section{Acknowledgements}

We are very grateful to Mr. Giorgis Chinasho for his constructive and invaluable support from the inception of this research work to its completion. My deepest thanks go to Wolaita Sodo University for giving me this chance to study. I owe a great deal of gratitude to instructors for giving information and allowing observing when they teach and the Department of physics students filling the questionnaires.

\section{Appendix}

Questionnaire for teachers: Dear respondents, the aim of this questionnaire is to obtain information on the implementation of active learning methods. Your cooperation to answer all the questions thoroughly and carefully is of great value and thus, your interest and devotion of time is vital. The information you give will be used only for academic purposes. Finally, the researchers would like to thank you in advance for your cooperation and devotion of time.

Instruction I: Please, put a tick (V) on your choice to indicate your practice of active learning methods.

Table 4. Implementation of Active learning methods by instructors.

\begin{tabular}{|c|c|c|c|c|}
\hline No. & Items & Always & Sometimes & Never \\
\hline 1 & Brainstorming & & & \\
\hline 2 & Buzz group & & & \\
\hline 3 & Crossover group & & & \\
\hline 4 & Demonstration & & & \\
\hline 5 & Discussion & & & \\
\hline 6 & Group work & & & \\
\hline 7 & Hot seating & & & \\
\hline 8 & Jigsaw & & & \\
\hline 9 & Microteaching & & & \\
\hline 10 & Peer teaching & & & \\
\hline 11 & Presentation & & & \\
\hline 12 & Project work & & & \\
\hline 13 & Question and answer & & & \\
\hline 14 & Report writing & & & \\
\hline 15 & Role-play & & & \\
\hline
\end{tabular}

Questionnaire for Students: Dear respondents, the aim of this questionnaire is to obtain information on the implementation of active learning methods. Your cooperation to answer all the questions thoroughly and carefully is of great value and thus your interest and devotion to time is vital. The information you give will be used only for academic purposes kept confidential. Finally, the researchers would like to thank you in advance for your cooperation and devotion of time.

Instruction I: Please, put a tick (V) on your choice to indicate how often it is practiced.

Table 5. Active learning practice by students.

\begin{tabular}{|c|c|c|c|c|c|}
\hline No. & Items & Always & Sometimes & Never & Remark \\
\hline 1 & How often do your instructors let you practice your subjects using microteaching? & & & & \\
\hline 2 & How often do your instructors give you brainstorming activities? & & & & \\
\hline 3 & How often do your instructors let you practice your subjects using role plays? & & & & \\
\hline 4 & $\begin{array}{l}\text { How often do your instructors give you classroom tasks that make you stand up and move } \\
\text { around the classroom? }\end{array}$ & & & & \\
\hline 5 & How often do your instructors ask you questions during the session progress? & & & & \\
\hline 6 & How often do your instructors let you discuss in pairs or in groups about a certain topic? & & & & \\
\hline 7 & How often do instructors give you home taken individual assignments and project works? & & & & \\
\hline 8 & How often do your instructors let you present topics in the classroom? & & & & \\
\hline 9 & How often do your instructors let you demonstrate topics in the classroom? & & & & \\
\hline
\end{tabular}


Table 6. Observation of the classroom on implementation of active learning methods.

\begin{tabular}{lll}
\hline No. & Items & Yes \\
\hline 1 & Brainstorming & No \\
2 & Buzz group & \\
3 & Crossover group & \\
4 & Demonstration & \\
5 & Discussion & \\
6 & Group work & \\
7 & Hot seating & \\
8 & Jigsaw & \\
9 & Microteaching & \\
10 & Peer teaching & \\
11 & Presentation & \\
12 & Project work & \\
13 & Question and answer & \\
14 & Report writing & \\
\hline
\end{tabular}

\section{References}

[1] Ahmed, A. K. (2013). Teacher-centered versus learnercentered teaching style. The Journal of Global business management, 9 (1): 22-34.

[2] American Psychological Association (2010). Publication Manual of the American Psychological Association. Washington DC: American Psychological Association.

[3] Barrett, A. M. (2007). Beyond the Polarization of Pedagogy: Models of Classroom Practice in Tanzanian Primary Schools. Comparative Education, 43 (2), 273-294.

[4] Bonwell C. C., and J. A. Eison, (1991) Active Learning: Creating Excitement in the Classroom, ASHEERIC Higher Education Report No. 1. Retrieved from: http://www4.ncsu.edu/unity/lockers/users/f/felder/public/Pape rs/Prince_AL.pdf.

[5] Cress well, J. W. (2003). Research Design: Qualitative, Quantitative, and Mixed Methods Approaches. Thousand Oaks, CA: Sage.

[6] Federal Democratic Republic Government of Ethiopia. (1994). Education and Training Policy.

[7] Harasim, L., Starr, R. H., Teles, L. \& Turnoff, M. (1997). Learning networks: A field guide to teaching and learning online. Cambridge, MA: Massachusetts Institute of Technology.

[8] Ministry of Education (2011). Higher Diploma Programme for Teacher Educators: A Handbook: Addis Ababa, Ethiopia.
[9] Robson, C. (2002). Real World Research. $2^{\text {nd }}$ ed. Oxford: Blackwell Publishers Ltd.

[10] Teacher Education System Overhaul (TESO). (2003). Handbook. Addis Ababa.

[11] The Federal Democratic Republic of Ethiopia. (2004). Growth and transformation plan 2010/11-2014/15. Addis Ababa.

[12] Weimer, M. (2002). Learner-centered Teaching. San Francisco: Jossey-Bass.

[13] Yamane, T. (1967) Statistics: An Introductory Analysis. $2^{\text {nd }}$ Edition, Harper and Row, New York.

[14] Takele T. (2021). Promoting active learning methods. Global Research and Development Journal for Engineering | Volume 6 | Issue 9 | August 2021 ISSN: 2455-5703.

[15] Fayombo, G. A., Babalola, B. J., Olaleye, Y. L. (2012). Cross institutional study of the causes of absenteeism among the university students in Barbados and Nigeria. Journal of Educational and Developmental Psychology 2 (1), 122-136 DOI: $10.5539 /$ jedp.v2n1p122.

[16] Paulson, D.R., and Faust, J. L. (2010). Active Learning for the College Classroom. California State University, Los Angeles, CA, 90032.

[17] Student Learning \& Outcomes Assessment; University of Rhode Island Office of Student Learning \& Outcomes Assessment University of Rhode Island, Kingston, RI 02881Retrieved. 